Vol 1, No 1, Juni 2020; 15-26

ISSN : 2723-3324

Available at: e-journal.sttberitahidup.ac.id/index.php/jan/index

\title{
Pengajaran Eskatologi dalam Pendidikan Agama Kristen di Sekolah
}

\author{
Simsoni Yosua Daud Patola ${ }^{1}$, sony.patola@yahoo.co.id \\ Oda Judithia Widianing ${ }^{2}$, ojudithia@yahoo.com
}

\begin{abstract}
An essential aspect of the doctrine of escatology is futuristic fact, namely the disclosure of a number of events that will occur in the future through prophecy in the past. For this reason Bible prophecy is the dominant focus in the investigation and discussion of the doctrine of eschatology. Eschatology is the most important doctrine that must be taught in the church, family, and school environment as Christian education material, the Doctrine of Eschatology is very important taught to students in schools, so that they understand it and take the attitude to repent and believe in Jesus Christ and obtain life-saving work. Everlasting, now while still alive on earth and later when Jesus comes the second time to pick up every believer By knowing eschatology, students can prepare themselves spiritually with a strong faith that Jesus will come a second time to pick up believers in the resurrection from the first stage of the dead and those who are still alive will experience the rapture to heaven. In Christian education in schools students must be taught that in the first stage of the resurrection the believers in the Old Testament era and the New Testament era will be raised from the grave, and the believers who are still alive at the time will be raptured, they will obtain a glorious body for and enter the feast of the Lamb of God. In Christian education it is necessary to put in place precautionary advice, encouragement to work faithfully, talent development, affirmation of responsibility for all actions, and noble hope for the day of the Lord's coming.
\end{abstract}

Keywords: escatology; Christian education

\begin{abstract}
Abstrak
Aspek penting dari ajaran eskatologi adalah fakta futuristik, yang merupakan wahyu tentang beberapa peristiwa yang akan terjadi di masa depan melalui nubuat masa lalu. Karena alasan ini, nubuat Alkitab menjadi pusat pemeriksaan dan diskusi tentang ajaran eskatologi. Eskatologi merupakan doktrin terpenting yang harus diajarkan dalam lingkungan gereja, keluarga, dan sekolah sebagai materi pendidikan agama Kristen, Doktrin Eskatologi sangat penting diajarakan kepada anak didik di sekolah, agar mereka memahaminya dan mengambil sikap untuk bertobat dan percaya kepada Yesus Kristus dan memperoleh karya keselamtan hidup yang kekal, sekarang ketika masih hidup di dunia dan nanti ketika Yesus datang kedua kali menjemput setiap orang percaya. Dengan mengetahui Eskatologi anak didik dapat mempersiapkan diri secara rohani dengan iman yang kuat bahwa Yesus akan datang kedua kali unuk menjemput orang-orang percaya pada kebangkitan dari antara orang mati tahap pertama dan orang-orang yang masih hidup pada saat itu akan mengalami pengangkatan ke
\end{abstract}

\footnotetext{
${ }^{1}$ Mahasiswa Pascasarjana Sekolah Tinggi Teologi Berita Hidup

${ }^{2}$ Dosen Teologi PAK Sekolah Tinggi Teologi Berita Hidup
} 
surga (the rapture to heaven). Dalam Pendidikan agama Kristen di sekolah anak didik harus diberikan pengajaran bahwa dalam kebangkitan tahap pertama orang-orang percaya pada zaman Perjanjian Lama dan zaman Perjanjan Baru akan dibangkitkan dari kubur, serta orang-orang percaya yang masih hidup pada saat akan diangkat (rapture), mereka akan memperoleh tubuh kemuliaan untuk dan masuk dalam pesta Anak Domba Allah. Dalam pendidikan agama Kristen perlu disisipkan adanya nasihat untuk berjaga-jaga, dorongan untuk bekerja dengan setia, pengembangan talenta, penegasan tentang tanggung jawab atas semua tindakan, dan pengharapan yang mulia akan hari kedatangan Tuhan.

Kata-kata kunci: eskatologi; pendidikan Kristen

\section{PENDAHULUAN}

Studi tentang akhir zaman (eskatologi), adalah salah satu dasar dari iman Kristen, sehingga pelajaran ini perlu diketahui, diajarkan dan dipercayai oleh setiap umat Allah termasuk siswa di sekolah. Tetapi karena banyaknya pendapat dan interpretasi tentang pelajaran kedatangan Tuhan Yesus yang kedua, sangat penting untuk menyajikan pelajaran ini dengan benar dan tepat seperti yang dikatakan oleh Firman Tuhan.

Kesalahpahaman eskatologi mengarah pada pengajaran yang salah bagi siswa. Kurangnya penguasaan pengajaran kedatangan Tuhan yang kedua kali dapat menyebabkan interpretasi yang menyimpang dan bahkan bertentangan dengan Firman Allah sendiri. Ada beberapa kesalahan dalam menafsirkan dan menyajikan pelajaran tentang kedatangan Tuhan Yesus yang kedua bukannya membangkitkan gairah, antusiasme dan harapan, kedamaian dan kemakmuran untuk menyambut kedatangan Yesus yang kedua. Sebaliknya, ia membawa serta perasaan takut, takut, kebingungan, dan penyesatan. Misalnya, seorang juru bicara radio, Harold Camping, memperkirakan pada abad ke-21 bahwa Hari Penghakiman akan datang pada 21 Mei 2011. Menurutnya itu adalah hari penghakiman. Sekitar 200 juta orang yang dipilih akan naik ke surga meninggalkan bumi yang menjadi seperti selama 5 bulan. Hidup benar-benar berakhir pada 21 Oktober di tahun yang sama. Dia secara agresif mengumumkan Hari Penghakiman itu di papan iklan, bangku-bangku di halte bus dan karavan di semua kota di Amerika Serikat. Relawannya melakukan perjalanan melalui Afrika dan Amerika Latin untuk menyebarkan pesan serupa. Banyak yang panik karenanya. Beberapa meninggalkan pekerjaan mereka, menyerahkan semua barang milik mereka dan bahkan bunuh diri. Itu kemudian terbukti hanya omong kosong. ${ }^{3}$ Faktanya adalah bahwa

3 https://www.liputan6.com/global/read/2630998/10-sekte-kiamat-yang-mengegerkan-dunia-padaabad-ke-20 diunduh selasa tanggal 03/12/2019 Jam. 16.00 
tidak terjadi kedatangan Tuhan Yesus seperti yang diberitakan. Akibatnya, umat Allah menjadi bingung, banyak dari mereka gelisah, beberapa bahkan disesatkan.

Sangat penting untuk mengajar eskatologi kepada siswa di sekolah agar mereka dapat mempersiapkan sebaik mungkin untuk menyambut kedatangan Tuhan Yesus yang kedua. Saat mengajar Pendidikan Agama Kristen (PAK) di sekolah, perhatian dan waktu yang cukup harus diberikan pada topik atau pelajaran ini. ${ }^{4}$ Topik atau pelajaran ini dimaksudkan untuk memperkuat iman siswa, membantu siswa mengubah sikap yang bukan kehendak Allah, dan mengajar siswa bahwa suatu hari, ketika Tuhan Yesus datang untuk kedua kalinya. Studi tentang eskatologi hanya disebutkan secara singkat ketika topik yang terkait dengan eskatologi diajarkan, misalnya ketika membahas kenaikan Tuhan Yesus ke surga.

\section{TINJAUAN ESKATOLOGI DALAM PENGAJARAN PAK}

\section{Pengertian Eskatologi}

Istilah Eskatologi berasal dari bahasa Yunani, eschatos yang mempunyai arti hal-hal yang terakhir, sedangkan logos mempunyai arti ilmu atau doktrin. Sehingga jika digabungkan kata ini mempunyai arti "doktrin tentang akhir zaman". Apa yang dimaksud, tentu saja, merujuk pada semua peristiwa yang terjadi sebelum, selama, dan setelah kedatangan Tuhan Yesus yang kedua. Eskatologi adalah studi tentang segala sesuatu yang terjadi sebelum atau bahkan setelah kedatangan Yesus yang kedua. ${ }^{5}$ Eskalotogi juga memiliki perluasan makna dalam hubungan dengan individu. Dalam kaitan dengan individu, maka yang dibicarakan adalah hal-hal yang berkaitan dengan kematian fisik, kekekalan, dan sesuatu yang disebut "masa antara" (intermediate state) yaitu suatu masa antara sesudah kematian seseorang dan sebelum kebangkitan kembali. Dalam hubungannya dengan dunia dan secara keseluruhan, eskatologi membahas mengenai kedatangan Kristus yang kedua, kebangkitan umum, penghakiman akhir dan kondisi akhir.

Eskatologi menurut ajaran Kristen terkait dengan pemenuhan janji Allah yaitu keselamatan yang sempurna di dalam Kristus. Harun Hadiwijono menyatakan bahwa menurut Alkitab, keselamatan di hari-hari terakhir ini memiliki dua aspek, telah ada keselamatan pada zaman akhir ini, tetapi di sisi lain dikatakan bahwa keselamatan masih di depan kita atau belum ada. Intinya adalah bahwa keselamatan yang diberikan Allah kepada orang-orang beriman bersifat "sementara" dan belum sempurna. Apa yang ada sekarang

${ }^{4}$ Bimo Setyo Utomo, "Menggagas Penerapan Pengajaran tentang Akhir Zaman dalam Pendidikan Agama Kristen di Tingkat Sekolah Dasar dan Menengah Pertama," Dunamis 1, No. 1 (2016), 74-87

${ }^{5} \mathrm{http}$ ://www.sarapanpagi.org/eskatolog i-1-vt232.html di unduh 03/11/2019 jam 17.00 WITA 
tidak sempurna. Namun apa pun yang ada adalah jaminan bahwa segala yang sempurna akan diberikan. $^{6}$

Dapat dikatakan bahwa kehidupan orang percaya tidak diarahkan pada kehidupan di dunia ini, tetapi pada apa yang akan datang. Harapan orang percaya Kristus harus didorong ke masa depan, yang merupakan akhir zaman; saat penuaian untuk membedakan antara yang baik dan yang jahat (Mat. 13:39-40,49; 24: 3; 28:20). Zaman ini disebut, dalam Efesus 1:10, zaman kepenuhan untuk menyatukan semua hal dalam Kristus sebagai kepala, baik di surga maupun di bumi. Karena itu, dalam 1 dan 2 Tesalonika dan 1 Korintus 15 kita diberitahu oleh rasul Paulus, agar harapan orang beriman diarahkan pada akhir zaman. Hadiwijono juga menyatakan bahwa kehidupan manusia saat ini terhubung dengan akhir zaman. Pada harihari terakhir, kita diberikan karakteristik keselamatan yang telah diberikan kepada kita, tetapi yang belum sepenuhnya menjadi milik kita. Meskipun kita telah diselamatkan, tetapi kita masih harus berusaha untuk menahannya (Flp. 3:12), berjuanglah dengan sungguhsungguh dalam pertempuran iman untuk mencapai kehidupan kekal, yang merupakan tujuan dari panggilan kita (1 Tim. 6:12). ${ }^{7}$

Kembalinya Kristus adalah datangnya penghakiman atas yang hidup dan yang mati. Karena itu kedatangan Kristus yang kedua kali bukanlah peristiwa yang tidak ada hubungannya dengan kehidupan sehari-hari saat ini. Segala sesuatu di dunia ini kemudian akan dibuka tutupnya, disingkapkan kedoknya, di hadapan Allah. ${ }^{8} 9$

Jadi, Eskatologi adalah sebuah pemahaman teologia, yang memaparkan mengenai peristiwa-peristiwa yang akan terjadi pada akhir zaman, seperti pengangkatan, kehidupan kekal, kematian kekal, kebangkitan, penghakiman, penghukuman, kiamat, langit baru dan bumi baru. Hal-hal tersebut akan terjadi pada masa kedatangan Tuhan Yesus yang kedua kali.

\section{Eskatologi dan Pendidikan Agama dalam PL}

Pengajaran tentang Eskatologi yang diajarkan kepada anak didik harus dimulai dengan dengan melihat fakta-fakta dalam Perjanjian Lama (PL) yang menjadi awal dari sebuah pembelajaran. Iman orang-orang percaya dalam PL adalah berorientasi pada hal-hal eskatologis, yang berpusat pada kedatangan Juruselamat. Hoekema mengatakan bahwa "Mereka menantikan kehadiran Allah dalam sejarah, baik dalam waktu dekat maupun jauh,

\footnotetext{
${ }^{6}$ Harun Hadiwijono, Iman Kristen (Jakarta: BPK Gunung Mulia, 2007), 471

${ }^{7}$ Ibid, 474

${ }^{8}$ Harun Hadiwijono, Inilah Sahadatku (Jakarta: BPK Gunung Mulia, 1995), 115-116

${ }^{9}$ H. L. Willmington, Eskatologi (Malang: Gandum Mas, 1997), 265-282
} 
Iman yang melihat ke depan inilah yang telah memberikan kepada orang percaya PL dasar untuk taat." $" 10$

Istilah Eskatologi memang tidak disebutkan secara eksplisit dalam dunia Perjanjian Lama. Tetapi orientasi seluruh PL adalah kepada eskatologi. Vriezen menyebutkan bahwa pandangan eskatologi dalam PL adalah "sebuah fenomena unik dari bangsa Israel dan tidak dijumpai di luar Israel" ${ }^{\text {11 }}$ Hoekema menunjukkan beberapa karakteristik eskatologis PL, salah satunya adalah Hari Tuhan ( יום יהוה ). Istilah יום diartikan dengan waktu yang sangat lama sekali, suatu musim tertentu dimana peristiwa luar biasa terjadi, seperti kemakmuran, kejayaan, dan bahkan suatu peristiwa penghakiman dan bencana. Jadi dapat dikatakan bahwa Hari Tuhan bisa merupakan suatu hukuman dan rahmat/kesenangan bagi setiap orang yang taat kepada hukum-hukum Allah akan menerima keselamatan hidup dan bagi setiap orang yang tidak taat akan menerima hukuman kekal.

Seorang guru agama Kristen harus memberi siswa pemahaman bahwa pada era Perjanjian Lama ada kepercayaan yang tumbuh dan populer bagi Israel tentang hari Tuhan, secara dramatis Tuhan akan campur tangan untuk membebaskan umat-Nya dan berbagai ketakutan dan penindasan. Biasanya setiap tahun diadakan pengurbanan sebagai peringatan, dengan harapan bahwa Israel akan makmur dan mengatasi musuh. Pertengahan abad ke- 8 SM diserukan bahwa kemakmuran yang diperoleh Israel adalah melalui pemerasan dan praktik agama palsu, dan ketika hari itu tiba itu akan menjadi nyata dan itu adalah hari penghakiman (Am. 5:18-27). A. Lamorte dan G. F. Hawthorne mengemukakan tentang nubuat dalam Dictionary of Teology, bahwa nubuat Perjanjian Lama dibagi menjadi tiga kategori utama. Pertama, nubuat tentang pengasingan orang Israel sebagai hukuman Allah atas dosa-dosa orang-orang pilihan, tetapi Allah berjanji untuk memulihkan atau memulangkan bangsa setelah masa pengasingan. Kedua, nubuat mesianis termasuk kedatangan Juruselamat dari Israel dan dunia (Yes 52: 13-53: 12; Mi 5: 1-2). Ketiga, nubuat eskatologis tentang peristiwa yang terjadi pada akhir zaman ketika Mesias kembali untuk mendirikan kerajaan Allah di bumi. ${ }^{12}$

Penaklukan Yerusalem pada tahun 586 sM dan pembuangan Israel Utara dipandang sebagai penggenapan nubuat Amos. Walau demikian pada suatu hari kelak pemerintahan Israel akan dipulihkan dan pemerintahan YHWH akan ditegakkan atas seluruh bumi (Yes. 40). Hari Tuhan atau Yom YHWH (יום יהוה) berisikan beberapa nubuat, yakni hari Tuhan

\footnotetext{
${ }^{10}$ Anthony A. Hoekema, Alkitab dan Akhir Zaman (Surabaya: Momentum, 2014), 15

${ }^{11}$ Ibid. hlm 4

${ }^{12}$ A. Lamorte dan G. F. Hawthorne "Prophecy" dictionary of teology
} 
yang mendatangkan penghukuman; bangsa Israel bertobat dan Tuhan akan mengembalikan dari pembuangan; Yerusalem akan dipulihkan dan Bait Allah akan dibangun kembali; Sang Mesias akan datang dari keturuan Daud dan akan memegang pemerintahan yang kuat; dan akhir zaman akan datang kemudian.

Sehubungan dengan akan adanya harapan di dalam tunas Daud, Yeremia mengkategorikan bahwa tunas Daud itu akan memerintah sebagai raja; ia akan berlaku bijaksana, bahwa raja yang akan datang adalah raja yang takut akan Allah, yang berbeda dengan raja-raja masa itu (Yer. 10:21); ia disebut sebagai keadilan yang memenuhi tugas sesuai dengan perintah ilahi; dan ia akan melaksanakan teori dan praktik hukum serta keadilan di atas bumi.

Jadi, pengajaran yang dilakukan oleh seorang pengajar pendidikan agama Kristen harus memperhatikan fakta-fakta penting dalam PL yang membahas tentang akhir zaman, sehingga dalam pengajarannya memiliki nilai-nilai Alkitabah yang dapat dipahami oleh anak didik dan tidak dapat terbantahkan oleh siapapun.

\section{Eskatologi dan Pendidikan Agama dalam PB}

Perjanjian Baru menunjukkan bahwa peristiwa eskatologis yang dinubuatkan para nabi Perjanjian Lama telah tergenapi, namun sekaligus penggenapannya yang final masih akan datang. Ini menjadi karakter utama eskatologi PB, already but not yet. Hal ini dijelaskan oleh Hoekema sebagai berikut :

Pertama, Perjanjian Baru menubuatkan peristiwa eskatologis besar dari Perjanjian Lama. Kedatangan Yesus Kristus ke dunia dinyatakan dalam Perjanjian Baru sebagai penggenapan nubuat Perjanjian Lama.

Kedua, manifestasi dari apa yang digambarkan oleh penulis Perjanjian Lama sebagai peristiwa yang sama dalam dua tahap pemenuhan ditemukan dalam Perjanjian Baru: masa mesianis sekarang dan masa depan.

Ketiga, hubungan antara dua tahap eskatologis adalah bahwa berkah hari ini adalah janji sekaligus jaminan berkah yang lebih besar di masa yang akan datang.. ${ }^{13}$

Di dalam surat Ibrani dinyatakan bahwa orang-orang tertentu pada zamannya telah menikmati karunia-karunia dunia yang akan datang. Paulus menegaskan hal ini dalam Ef. 2:7 "supaya pada masa yang akan datang (en toisaisontoiseperchomenois) Ia menunjukkan kekayaan kasih karunia yang melimpah sesuai dengan kebaikan-Nya terhadap kita dalam Yesus Kristus.” Ada hal yang menarik dari pemakaian kata benda synteleia (akhir atau penggenapan), ketika kata ini digunakan dengan bentuk jamak dari kata aion (zaman), maka artinya adalah zaman sekarang ini.

\footnotetext{
${ }^{13}$ Hoekema, hlm. 27
} 
Keindahan eskatologi bagi iman orang-orang percaya yang digambarkan dalam PB sekaligus berlaku hingga jemaat segala zaman adalah adanya pengharapan Kristen yang berdasar pada suatu kepastian Kristus akan kembali menjemput milik-Nya. Maka guru PAK perlu memotivasi para murid untuk terus memandang kepada Hari Tuhan ini selagi mereka berjerih lelah mengikut Tuhan, melayani Dia, dan memelihara iman sampai garis akhir. Di tengah dunia yang tidak memberi kepastian, para murid yang mengalami arus deras dunia dan pengaruhnya harus ditolong melalui pengajaran eskatologi untuk melihat segala akhir kesuraman dunia akan digantikan dengan kemuliaan ilahi kelak secara final dalam diri mereka.

\section{RELASI ESKATOLOGI DAN PENDIDIKAN PENDIDIKAN KRISTEN}

\section{Hakikat dan Tujuan PAK}

Pendidikan Agama Kristen pada prinsipnya didasarkan pada konsep kekristenan, yaitu pendidikan yang berpusat pada Kristus. B. Samuel Sidjabat mengutip pandangan Robert W. Pazmino yang mendefinisikan bahwa Pendidikan Kristen adalah upaya yang sederhana dan sistematis yang didukung oleh upaya spiritual dan manusiawi untuk memberikan pengetahuan, nilai-nilai, sikap, keterampilan dan perilaku yang sesuai dengan iman Kristen. Berusaha keras untuk perubahan, pembaruan, dan reformasi individu, kelompok, dan bahkan struktur melalui kuasa Roh Kudus sehingga siswa hidup sesuai dengan kehendak Allah, sebagaimana dinyatakan dalam Alkitab, khususnya dalam Yesus Kristus. ${ }^{14}$

Mengenai peran Roh Kudus dalam pendidikan agama Kristen, lebih jauh Budiyana mengemukakan bahwa Roh Kudus berperan dalam meyakinkan guru dan murid akan kebenaran pesan dari Allah. Pada pendidikan agama Kristen yang tidak mengandalkan Roh Kudus, indikasinya adalah muncul ketidakpercayaan. ${ }^{15}$ Roh Kudus memberikan kesanggupan untuk mengerti akan Firman Allah setiap waktu. Tanpa Roh Kudus, tak ada seorang manusia pun yang dapat memahami kehendak dan maksud Allah dalam kehidupannya. ${ }^{16}$ Pendidikan Kristen adalah sebuah tugas supernatural dimana Allah Roh

\footnotetext{
${ }^{14}$ B. Samuel Sidjabat, Strategi Pendidikan Kristen (Yogyakarta: Andi Offset, 1994), 10

15 Hardi Budiyana, "Roh Kudus Dalam Proses Pembelajaran Pendidikan Kristen Mewujudkan Pengajaran Kristen Yang Mengandung Nilai Kekal," Jurnal Teologi Berita Hidup 1, no. 1 (2018).

${ }^{16}$ Asih Rachmani Endang Sumiwi, "Peran Roh Kudus dalam Kehidupan Orang Percaya Masa Kini," Jurnal Teologi El-Shadday 1, no. 1 (2016): 55-68.
} 
Kudus memegang peran yang sangat vital, sebuah proses mengomunikasikan kebenaran Allah Tritunggal untuk memuridkan jiwa. ${ }^{17}$

Hakikat PAK yang dimaksud di atas adalah pengembangan makna dari PAK yang dirumuskan oleh E.G. Homrighausen dan I.H. Enklaar dalam Konferensi PAK di Sukabumi pada tahun 1955. Rumusan itu memberikan arti yang sedalam-dalamnya dari PAK, bahwa dengan menerima pendidikan itu, semua yang belajar, baik muda maupun tua, memasuki persekutuan iman yang hidup dengan Tuhan sendiri, sehingga oleh dan dalam Dia mereka terhisab pula pada persekutuan jemaat-Nya yang mengakui dan mempermuliakan nama-Nya di segala waktu dan tempat."18

PAK di sekolah pada dasarnya adalah pendidikan yang disajikan kepada setiap siswa secara terencana, sistematis, dan berkesinambungan untuk memahami cinta dan pekerjaan Allah dalam kehidupannya, dan untuk membantu siswa mengubah nilai-nilai Kristen setiap hari. Konferensi Kurikulum I PAK yang diselenggarakan oleh KOMPAK DGI di Sukabumi, 12 Juni s/d 14 Juli 1963, merumuskan tujuan PAK adalah mengajak, menolong, dan menghantar untuk mengetahui kasih Allah yang sejati dalam Yesus Kristus, sehingga dia dapat datang ke dalam persekutuan dengan Allah di bawah bimbingan Roh Kudus. Ini terbukti dalam kasihnya kepada Allah dan sesamanya, yang ia jalani dalam kehidupannya sehari-hari, baik dengan perkataan maupun tindakan sebagai anggota tubuh Kristus. ${ }^{19}$

Dengan sedikit memodifikasi tujuan PAK di atas, Oditha Hutabarat dan Wiwik Estiawan merumuskan PAK di sekolah upaya terencana dan berkesinambungan untuk mengembangkan kapasitas siswa sehingga, dengan bantuan Roh Kudus, mereka dapat memahami dan menghayati kasih Allah dalam Yesus Kristus yang dinyatakan dalam kehidupan sehari-hari mereka, terhadap orang lain dan lingkungan mereka. ${ }^{20}$

Atas dasar tujuan PAK di atas, tiga tujuan inti PAK dapat ditetapkan di sekolahsekolah, yaitu pengenalan Allah Bapa, Putra dan Roh Kudus dan karya-karya-Nya; penciptaan bangsa Indonesia yang mampu menghayati iman mereka secara bertanggung jawab dalam masyarakat majemuk; dan menanamkan pemahaman tentang Tuhan dan

${ }^{17}$ Oda Judithia Widianing, "Pendidikan Kristen di Sekolah: Sebuah Tugas Ilahi Dalam Memuridkan Jiwa," Jurnal Teologi Berita Hidup 1, no. 1 (2018): 78-89. 2004), 26

${ }^{18}$ E. G. Homrighausen dan I. H. Enklaar, Pendidikan Agama Kristen (Jakarta: BPK Gunung Mulia,

19 Jedida T. Posumah-Santosa, Pendidikan Agama Kristen di Sekolah, dalam Andar Ismail (Peny.), Ajarlah Mereka Melakukan (Jakarta: BPK Gunung Mulia, 2004), 158

${ }^{20}$ Oditha Hutabarat dan Wiwik Estiawan, Kurikulum Pendidikan Agama Kristen Berbasis Kompetensi Sekolah Dasar (Jakarta: Bagian Proyek Peningkatan Wawasan Kependidikan Guru Agama Ditjen Dikdasmen Depdiknas, 2003), 3 
pekerjaan-Nya pada siswa, sehingga mereka dapat memahami dan menghargai pekerjaan Tuhan dalam kehidupan manusia.

Menurut penulis hubungan anatara eskatologi dan Pendidikan Agama Kristen di sekolah pada hakikatnya adalah upaya yang dilakukan oleh guru PAK kepada anak didik secara terencana yang dirumuskan dalam sebuah kurikulum yang sistematik dan diajarkan dalam proses belajar dan mengajar secara terus menerus mengenai peristiwa yang akan terjadi pada akhir zaman, terutama mengenai kematian kekal, pemghukuman, dan hidup kekal bersama Yesus, sehingga mampu membentuk karakter siswa untuk menerima Yesus sebagai Juruselamat, hidup dalam pertobatan dan menjalankan kehidupan baru dalam kasih karunia Allah, serta memiliki mental Kristen yang mampu menjadi saksi Kristus ditengahtengah kehidupan masyarakat.

\section{Pengajaran tentang Eskatologi di Sekolah}

Sekolah merupakan wadah yang disediakan oleh pemerintah untuk mendidik siswa dalam berbagai ilmu pengetahuan, termasuk di dalamnya pemerintah telah merancang kurikulim K13 untuk mata pelajaran pendidikan Agama Kristen, pengajaran PAK di sekolah merupakan tugas pokok guru PAK. Pengajaran mengenai eskatologi sangat penting karena banyak siswa yang belum mengetahui apa yang akan terjadi pada akhir zaman, sehingga iman mereka masih bimbang mengenai keselamatan. Walaupun tidak seorang pun yang tahu persis kapan Tuhan Yesus akan kembali, setiap orang yang percaya dan ingin menyambut kedatangan-Nya kembali harus memiliki sikap yang benar. Maka ketika mengajar PAK di sekolah tentang eskatologi, titik tekan bukan pada kapan hari kedatangan Tuhan tiba, tetapi ada sejumlah hal yang perlu mendapat penekanan sikap yang benar dalam menyambut kedatangan-Nya.

Perlu ada nasihat untuk berjaga-jaga. PAK di sekolah perlu mengajarkan siswa untuk berjaga-jaga dalam menantikan kedatangan Tuhan. Kewaspadaan diperlukan karena kedatangan-Nya tidak dapat diprediksi sebagaimana telah dinyatakan di atas. Ketika kehidupan sehari-hari terjadi secara normal, semuanya berjalan secara teratur, hari kedatangan Tuhan itu tiba. Tuhan Yesus telah berkata, bahwa masa itu terjadi seperti pada zaman Nuh. Sebelum Nuh masuk ke dalam bahtera dan air bah datang, orang-orang makan dan minum, kawin dan mengawinkan, dan mereka tidak tahu bahwa tiba-tiba hal itu terjadi dan mengejutkan mereka. Demikian pula kedatangan Anak Manusia terjadi secara tiba-tiba pada saar segala hal tampat seperti normal.” (Mat.24:38,39). 
Perlu ada dorongan untuk bekerja dengan setia. Tuhan tidak ingin umat-Nya hanya bersikap pasif ketika menantikan kedatangan-Nya, sebaliknya harus terlibat dalam memenuhi semua tugas yang telah diberikan-Nya. Apapun tugas yang diterima, tidak ada yang dapat dianggap sebagai tugas yang kurang mulia sehingga tidak dikerjakan, termasuk tugas sebagai siswa untuk belajar. Inilah sebabnya ada perumpamaan tentang hamba yang setia dan jahat yang diajarkan Tuhan Yesus di dalam Matius 24: 45-51. Rasul Paulus juga mengajar jemaat agar segala sesuatu dilakukan seperti untuk Tuhan dan bukan seperti untuk manusia (Kol. 3:23).

Perlu ada upaya pengembangan talenta yang diberikan Tuhan. Dalam perumpamaan Tuhan Yesus tentang talenta yang tertulis di dalam Matius 25: 14-30, pengembangan talenta jelas membutuhkan kesetiaan. Penting untuk menekankan bahwa masalahnya bukanlah seberapa banyak bakat yang dimiliki dan berapa banyak yang dihasilkan. Tetapi yang ditekankan oleh Yesus adalah kesetiaan dalam mengembangkan talenta tersebut.

Perlu ada penegasan tentang pertanggungjawaban atas semua tindakan. Penekanan dalam mengajarkan PAK kepada siswa di sekolah adalah untuk memberi siswa puncak pemahaman dan penghayatan, bahwa ketika Yesus datang untuk kedua kalinya Ia akan menjadi hakim yang akan menghakimi seluruh umat manusia. Penekanannya adalah pada mendorong siswa untuk menyambut kedatangan keduanya sedini mungkin sehingga siswa dan orang Kristen pada umumnya dapat benar-benar memahami dan mengetahui bahwa mereka bertanggung jawab atas apa yang Tuhan Yesus lakukan di dunia.

Perlu selalu disegarkan pengharapan akan hari yang mulia. Hal terpenting dari eskatologi adalah adanya pengharapan akan akhir hidup orang percaya, yaitu masuk ke dalam kehidupan kekal yang penuh dengan kemuliaan. Hal itu seperti dikatakan oleh Arnold T. Olson "Sejak hari-hari pertama gereja Kristen, kaum Injili telah 'mencari pengharapan yang diberkati itu, dan penampakan mulia dari Allah yang agung dan Juruselamat kita Yesus Kristus ${ }^{21}$ Pengharapan ini harus disegarkan lagi dan lagi, dalam kognitif dan afektif para siswa, bahwa pekerjaan mereka dalam Kristus, kesucian hidup yang mereka perjuangkan sekarang dan kesetiaan kepada iman dalam segala kondisi tidak akan pernah sia-sia. Hidup mereka di dalam Kristus sangat berharga. Kesulitan yang dialami pada saat ini tidak akan bertahan selamanya dan tidak akan layak akan kemuliaan yang akan mereka terima.

${ }^{21}$ James Montgomory Boice, Dasar-Dasar Iman Kristen (Surabaya: Momentum, 2011), 815 
Pengharapan ini perlu disegarkan selalu dalam kognitif dan afektif murid bahwa jerih lelah mereka dalam Kristus, kekudusan hidup yang mereka perjuangkan saat ini, dan kesetiaan pada iman percaya dalam kondisi apapun tidak akan pernah sia-sia. Hidup mereka di dalam Kristus adalah hidup yang sangat berharga. Kesusahan yang dialami saat ini hanya merupakan kesusahan sementara dan tidak akan sebanding dengan kemuliaan yang akan mereka terima. Olson mengatakan bahwa bagi masalah-masalah dunia ini solusi akhir ada di tangan Sang Raja di atas segala raja, pada suatu hari Ia akan memerintah atas semua kerajaan-kerajaan dunia ini. ${ }^{22}$ Betapa indahnya jika setiap guru PAK dapat membawa sukacita eskatologi dalam diri siswa. Sukacita dan pengharapan bahwa Tuhan datang segera dan Ia akan membawa upah sebagai balasan bagi setiap orang menurut perbuatannya. ${ }^{23}$

Jadi, pengajaran eskatologi di sekolah sangat penting untuk menumbuhkan iman anak didik. Guru PAK harus menjelaskan secara tegas bahwa kedatangan Yesus yang kedua kali ke dunia adalah untuk membangkitkan orang percaya dan orang yang tidak percaya, mereka akan dihakimi dan akan mendapat upah mereka, orang yang percaya kepada Yesus Kristus akan memperoleh hidup yang kekal di sorga, sedangkan orang yang menolak untuk tidak percaya akan dihukum dan mengalami kematian kekal di neraka.

\section{KESIMPULAN}

Setelah membahas panjang lebar mengenai pengajaran Eskatologi dalam Pendidikan Agama Kristen di sekolah, maka penulis menyimpulkan, hal-hal sebagai berikut: Pertama, guru PAK harus memahami bahwa pengajaran tentang Eskatologi yang diajarkan kepada anak didik harus dimulai dengan dengan melihat fakta-fakta dalam Perjanjian Lama (PL) yang menjadi awal dari sebuah pembelajaran. Iman orang-orang percaya dalam PL adalah berorientasi pada hal-hal eskatologis, yang berpusat pada kedatangan Juruselamat, yaitu Yesus Kristus yang akan menebus dosa semua manusia yang ada di muka bumi ini.

Kedua, guru PAK harus menjelaskan bahwa Perjanjian Baru menunjukkan bahwa peristiwa eskatologis yang dinubuatkan para nabi Perjanjian Lama sebagian telah tergenapi dalam pribadi Yesus Kristus dalam kelahiran-Nya, dalam pelayanan-Nya, dalam kesengsaraan, kematian dan kebangkitan-Nya yang membawa kemenangan dalam mengalahkan kuasa maut, serta kenaikan-Nya ke surga untuk menyediakan tempat bagi semua orang yang percaya kepada-Nya.

\footnotetext{
22 Ibid

23 Wahyu 22:12
} 
Ketiga, pengajaran tentang eskatologi harus berpusat kepada Yesus Kristus sebagai satu-satunya Juruselamat manusia, hal ini penting agar iman anak didik semakin kuat agar dapat menjadi saksi bagi keluarga dan setiap orang yang ada di sekitarnya. Terkait dengan hal-hal yang menyangkut kedatangan Tuhan yang kedua, dalam pendidikan agama Kristen perlu disisipkan adanya nasihat untuk berjaga-jaga, dorongan untuk bekerja dengan setia, pengembangan talenta, penegasan tentang tanggung jawab atas semua tindakan, dan pengharapan yang mulia akan hari kedatangan Tuhan. Tujuan utama dari pendidikan agama Kristen adalah siswa menerima Yesus sebagai Tuhan dan Juruselamat dalam hidupnya.

\section{REFERENSI}

Beyer, Ulrich. Garis-Garis Besar Eskatologi Dalam Perjanjian Baru. Jakarta: BPK Gunung Mulia, 2001.

Boice, James Montgomory. Dasar-Dasar Iman Kristen. Surabaya: Momentum, 2011

Bolkestein. M.H. Kerajaan yang Terselubung. Jakarta; BPK. Gunung Mulia. 1999

Browning. W.R.F. Kamus Alkitab. Jakarta; BPK Gunung Mulia. 2007

Budiyana, Hardi. "Roh Kudus Dalam Proses Pembelajaran Pendidikan Kristen Mewujudkan Pengajaran Kristen Yang Mengandung Nilai Kekal.” Jurnal Teologi Berita Hidup 1, no. 1 (2018).

Hadiwijono, Harun. Iman Kristen. Jakarta: BPK Gunung Mulia, 2007. .Inilah Sahadatku. Jakarta: BPK Gunung Mulia, 1995.

Hoekema, Anthony A. Alkitab dan Akhir Zaman. Surabaya: Momentum, 2014

Homrighausen, E. G. dan I. H. Enklaar. Pendidikan Agama Kristen. Jakarta: BPK Gunung Mulia, 2004

Hutabarat, Oditha dan Wiwik Estiawan. Kurikulum Pendidikan Agama Kristen Berbasis Kompetensi Sekolah Dasar. Jakarta: Bagian Proyek Peningkatan Wawasan Kependidikan Guru Agama Ditjen Dikdasmen Depdiknas, 2003.

Ismail (Peny.). Ajarlah Mereka Melakukan. Jakarta: BPK Gunung Mulia, 2004.

Kittel, Theological Dictionary of the New Testament Vol II, Gerhard Kittel (ed), (Michigan; WM. B. Elrdmans Publishng Company, Grand Rapids.

Sidjabat, B. Samuel. Strategi Pendidikan Kristen. Yogyakarta: Andi Offset, 1994.

Sumiwi, Asih Rachmani Endang. "Peran Roh Kudus dalam Kehidupan Orang Percaya Masa Kini." Jurnal Teologi El-Shadday 1, no. 1 (2016): 55-68

Susanto, Hasan. Perjanjian Baru Interlinier Yunani-Indonesia dan Konkordansi Perjanjian Baru. Jakarta; Lembaga Alkitab Indonesia. 2004

Tomatala, Jacob. Paulus Hidup, karya dan Teologinya. Yogyakarta: Kanisius \& Jakarta: BPK. Gunung Mulia, 1983.

Utomo, Bimo Setyo. "Menggagas Penerapan Pengajaran tentang Akhir Zaman dalam Pendidikan Agama Kristen di Tingkat Sekolah Dasar dan Menengah Pertama." Dunamis 1, No. 1 (2016), 74-87

Wahono, Wismoady. Di Sini Kutemukan. Jakarta; BPK. Gunung Mulia, 1994

Widianing, Oda Judithia. "Pendidikan Kristen di Sekolah: Sebuah Tugas Ilahi Dalam Memuridkan Jiwa.” Jurnal Teologi Berita Hidup 1, no. 1 (2018): 78-89.

Willmington, H. L. Eskatologi. Malang: Gandum Mas, 1997. 